\title{
Unser langjähriger Zusammenarbeitspartner, die WIROMA AG, offeriert ein einmaliges Angebot: das Speicherfoliensystem Proscan 35E
}

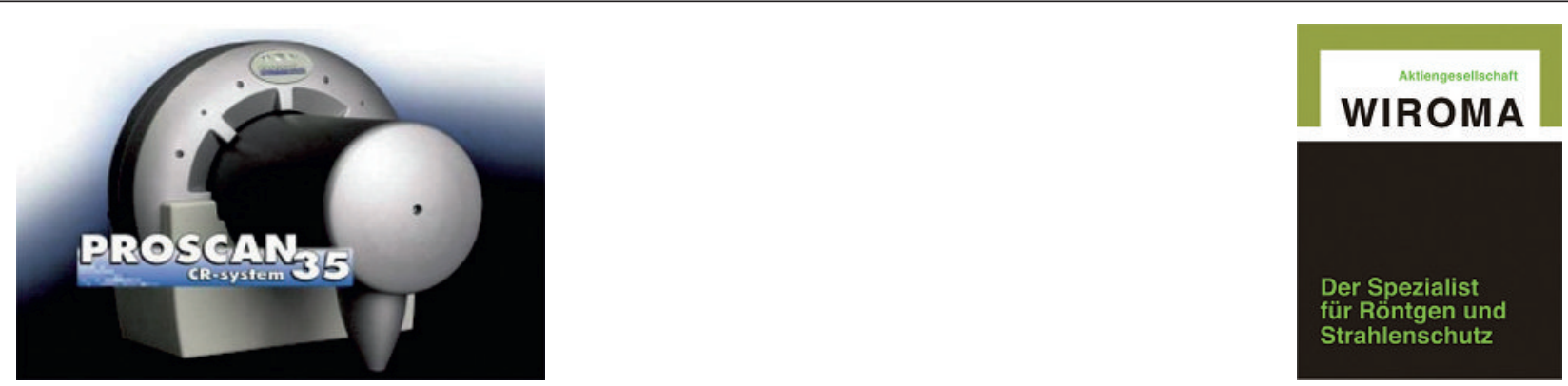

\section{Das in Schweizer Arztpraxen bewährte und über 100fach installierte Proscan}

- Auslesegerät Proscan 35

- PC mit Befundungsmonitor 21,4" (inkl. Grafikkarte)

- Akquisitions-Software mit Modul AIP-Filter (automatische Bildoptimierung) und Modul zur Anbindung an ein Patientenverwaltungsprogramm

- 3 Speicherfolien mit Kassetten $(18 \times 24 \mathrm{~cm}, 24 \times 30 \mathrm{~cm}, 35 \times 43 \mathrm{~cm})$

- Diagnose-Software mit Modul zum Brennen einer Patienten-CD

- Tintenstrahl-Drucker zum Patienten-CD beschriften

- Backup-Lösung (Hard- und Software) inbegriffen

- Installation und Abnahmeprüfungen inbegriffen

\section{Zum unschlagbaren Preis von 29900 CHF (inkl. 8,0\% MwSt.)}

(Gültigkeit bis 30.4.2011)

\section{Die Wiroma AG bietet auch preisgünstige $\mathrm{DR}^{*}$-Systeme an}

* DR-System = Direct Radiography System (Flat Panel).

\section{Gerne beraten wir Sie kostenlos und unverbindlich}

Ich/wir sind interessiert an:

$\square$ Beratung/Planung

$\square$ Film/Chemie

$\square$ Digitalem Röntgen

Name/Vorname

Adresse

PLZ/Ort

Datum

Telefon Privat/ Geschäft

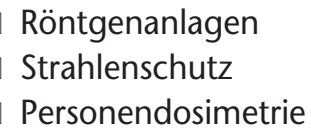

